\title{
PSYCHOLOGICAL TYPE AND \\ SALES ORIENTATION-CUSTOMER ORIENTATION
}

\author{
Kenneth E. Bass \\ Frederic J. Hebert \\ East Carolina University \\ Greenville, NC
}

\begin{abstract}
A business firm expects that salespersons' degree of customer orientation will be compatible with the extent to which the firm itself has adopted the marketing concept. Customer orientation is an important behavior on the part of salespersons, yet it has received relatively little attention from organizational researchers. Differing psychological types show promise as a tool by which a salesperson's performance can be predicted. This exploratory research was designed to evaluate the relationships between individuals' psychological type preferences and their customer orientation. This study found Jungian psychological types to be significantly related to salespersons' customer orientation. These findings suggest that personality types can play a supplemental role in salesperson selection and training. Managerial implications and suggestions for future research are also presented.
\end{abstract}

\section{Introduction}

The marketing concept suggests that business firms should adopt an external focus, thus concentrating on building long-term cooperative and mutually beneficial relationships with customers by identifying and satisfying their needs. However, the extent to which an individual firm adopts the marketing concept is determined by its overall concern with customer needs and competitive actions. Once a firm decides the degree to which it will adopt the marketing concept, it should act to insure that this strategy is reflected in the customer orientation of its salesforce (Siguaw, Brown, and Widing, 1994). Customer orientation can be defined as the application of the marketing concept at the salesperson-customer level. In contrast, a sales orientation calls for a business firm to make its offerings available with less regard for customer needs (Saxe and Weitz, 1982). A customer orientation is important in that individuals who practice a high level of customer orientation behave in ways that increase satisfaction of their customers (Dunlap, Dotson, and Chambers, 1988).

Though customer-oriented selling is an established practice on the part of salespeople, understanding of this behavior and its antecedents is incomplete. However, some individuals seem to innately behave in a more customer oriented 
manner than others (Dunlap, Dotson, and Chambers, 1988; Williams and Weiner, 1990). Saxe and Weitz (1982) suggested that a number of situational variables and individual differences constructs such as inner-outer directedness and selfmonitoring may be related to customer orientation. Are there other measurable differences among individuals that might differentiate those who are customer oriented from those who are sales oriented? A number of researchers have suggested that differences in personality factors may influence job behavior (e.g., Bass and Hebert, 1993; Hoy and Hellriegel, 1982; Porter and Miles, 1974; Sager and Ferris, 1986). Differing Jungian psychological types (Jung, 1971) have been shown to influence individuals' behavior in a number of organizational situations (e.g., Hoy and Hellriegel, 1982; Nutt, 1990; Ruble and Cosier, 1990). Psychological tests based on Jung's theory are widely used by business firms for purposes such as team building and management development (Gardner and Martinko, 1996). Such differing psychological types may also influence the customer orientation of salespersons. Little empirical research has examined potential relationships between personal variables and customer orientation. This dearth of research calls for further investigation.

The purpose of this exploratory research was to investigate potential effects of differing psychological types upon individuals' customer orientation. The potential association between these divergent psychological types and customer orientation could be of great importance to managers as well as researchers. Psychological types might be useful as supplemental decision criteria for salesperson hiring and training decisions if such types prove to be significant antecedent variables of customer orientation.

The next section of this paper provides a brief literature review, theoretical rationale, and research questions. We then present the research methodology and discuss the findings of the study. Finally, implications for management practice and future research are presented.

\section{Literature Review and Theoretical Rationale}

\section{Sales Orientation and Customer Orientation}

The marketing concept has been a cornerstone of marketing thought for many years. This concept calls for an organization to focus on its customers, determine their needs, and then fill those needs more effectively than competitors while meeting its own goals through an integrated organizational effort (Houston, 1986; Saxe and Weitz, 1982). Customer-oriented selling is compatible with the marketing concept. Saxe and Weitz defined customer-oriented selling as "...the practice of the marketing concept at the level of the individual salesperson and customer" (343). In contrast, the selling concept calls for an organization to increase demand for its products. By embracing a selling orientation, a salesperson attempts to increase sales volume by using techniques such as high-pressure selling with little regard for the needs of the customer. 
The market orientation of a firm is determined by the extent to which the firm adopts the marketing concept as a business philosophy (Saxe and Weitz, 1982). The marketing concept has been recommended almost universally as an optimal strategy for business firms. However, it may not be an appropriate strategy for all organizations (Houston, 1986). Some researchers have suggested that a firm consider its external environment and internal capabilities and requirements in making a choice between a market-oriented and a sales-oriented strategy (Houston, 1986; Kohli and Jaworski, 1990; Narver and Slater, 1990). Once one of these strategies is selected and established by a firm, that firm can be expected to likewise influence its salesforce to embrace and practice the adopted philosophy in their selling efforts (Siguaw, et al., 1994).

A firm may use a number of practices to influence the degree of customer orientation practiced by its salesforce. For example, a high degree of customer orientation may be established and maintained through salesforce training and by rewarding customer oriented behaviors such as helping customers assess their needs and offering products that will satisfy those needs. On the other hand, an organization can establish and reinforce a selling orientation by rewarding behaviors such as high-pressure selling with little regard for building long-term customer relationships.

A firm may reasonably expect that salespeople will adopt a customer orientation consistent with the firm's degree of market orientation. As stated earlier, a firm can train and reward its salesforce to develop and maintain a customer orientation consistent with the degree of market orientation of the firm. However, a salesperson's customer orientation may diverge from the market orientation of the firm. Some individuals may naturally act in a more customer oriented manner than others and are more easily able to learn to do so (Williams and Weiner, 1990).

Saxe and Weitz (1982) developed and validated a scale, the Sales Orientation-Customer Orientation (SOCO) scale, in order to measure sales orientation and customer orientation of salespeople. Since that time, a number of empirical studies have been conducted which investigated sales-oriented and customer-oriented behaviors. For example, Kelley (1992) found that salespersons' perceptions of the organizational climate impact on their customer orientation. In another study, Dunlap, Dotson, and Chambers (1988) surveyed residential real estate brokers and customers and found conflicting perceptions among customers and brokers regarding the extent to which the brokers were customer oriented. Brokers rated themselves to be significantly more customer oriented when the broker results were compared with the rating of the customers who were surveyed. O'Hara, Boles, and Johnston (1991) investigated a set of personal variables as antecedents to customer orientation. These researchers found that organizational commitment was related to selling style, but other personal variables such as job tenure and gender were found to be situation dependent. In a more recent study of industrial salespeople, Siguaw, et al. (1994) found that salesper- 
sons' customer orientation was significantly influenced by the market orientation of the firm.

\section{Psychological Types}

Jung's (1971) theory of psychological type provides a framework for defining and evaluating individual differences in organizational behavior. Two psychological dimensions of particular importance in management and marketing research are the ways that individuals acquire information and the ways that they make decisions about the information that has been acquired (Ruble and Cosier, 1990). Jung referred to these dimensions respectively as perception and judgment. He proposed that individuals develop one of two dominant ways to perceive information about their environment: sensing (S) or intuition $(N)$. The $S$ psychological type individuals prefer information that is factual, precise, concrete, and practical, which is derived from their senses. The $\mathrm{N}$ type individuals prefer to acquire holistic information by examining an entire situation and focusing on its overall meaning. Jung also proposed that individuals develop one of two dominant ways to judge information to make decisions: thinking $(T)$ or feeling $(F)$. The $T$ psychological type individuals reason by using logic to make rational judgments or decisions. The $\mathrm{F}$ type individuals stress value judgments, and prefer to reason and make decisions based in terms of personal and subjective values (Ginn and Sexton,1990).

According to Jung, individuals do not operate through both $\mathrm{S}$ and $\mathrm{N}$ modes simultaneously, but have a preference for one of the two modes for perception. Likewise, individuals do not operate through both $\mathrm{T}$ and $\mathrm{F}$ modes simultaneously, but have a preferred mode of judgement (Herden and Lyles, 1981). Empirical research based on differing psychological types has reported significant effects in many areas of organizational performance.

A number of empirical studies have evaluated possible linkages between differing Jungian psychological types and individual differences variables of interest to organizational managers and researchers. A comprehensive literature review concerning psychological types and personal characteristics and behaviors of managers is beyond the scope of this paper, although such a review is presented by Gardner and Martinko (1996). We provide a selective overview of this literature below.

Kilmann and Mitroff (1976) investigated the effects of different psychological types on organizational preferences. These researchers found that subjects' concepts of an ideal organization differed by psychological type. Kilmann and Thomas (1975) confirmed that differing psychological types are related to preferred methods of conflict resolution. Ts were found to be more assertive and less cooperative than Fs, and Fs were found to be more accommodating. Nutt (1990) investigated the effects of managers' various psychological types on decision making under varying degrees of uncertainty. The combination of $S$ and $F$ types were found to be less risk averse and to adopt more projects than other combina- 
tions. Gardner and Martinko (1990) studied the relationships between psychological type and managerial effectiveness. High school principals who preferred the $S$ type were found to perform at higher levels than individuals preferring the $\mathrm{N}$ function. However, other studies contradict these findings (Gardner and Martinko, 1996). Ginn and Sexton (1990) compared psychological types of entrepreneurs whose businesses were classified as high-growth with those of entrepreneurs whose businesses were classified as slow-growth. Entrepreneurs who were oriented toward growth preferred the $\mathrm{N}$ personality type for receiving information and the $\mathrm{T}$ type for making decisions.

This present research is exploratory in nature and is intended to examine possible effects of psychological types upon customer orientation. Since psychological types have been shown to affect several different types of behavior in organizations, it is reasonable to expect that differing psychological types will also affect the attitude toward selling behavior as well as the selling behavior of salespersons. Owing to the dearth of literature in this area, we decided to engage in an exploratory research effort to examine the relationships between various Jungian personality types and salespersons' customer orientation. Therefore, the following research questions are posited:

\begin{abstract}
R1: Is there a statistically significant difference in SOCO scores between individuals who prefer a sensing function compared with those who prefer an intuitive function?
\end{abstract}

R2: Is there a statistically significant difference in SOCO scores between individuals who prefer a thinking function compared with those who prefer a feeling function?

\title{
Methodology
}

\section{Sample and Data Collection}

A student sample was judged to be appropriate for this study since our purpose was to assess relationships between psychological types and innate customer orientation, thereby focusing on subjects prior to sales training by an organization.

Participants in this study were 123 senior business students enrolled in business policy and strategy courses and graduate students enrolled in a graduate course in Management in a large Mid-Atlantic university. All of the subjects were business majors. Participation was voluntary, and students were assured that their responses were anonymous. About 49 percent were seniors while 51 percent were MBA students. Respondents ranged in age from 21 to 48 years, with a mean age of approximately 25 years. Of the 123 respondents, 56 percent were male and 44 percent were female. None of the subjects had previous employment as a salesperson. 


\section{Measures}

Sales Orientation-Customer Orientation. Saxe and Weitz (1982) developed and validated a scale to measure sales orientation and customer orientation (SOCO) of salespersons. The SOCO scale is composed of 24 items that relate to specific behaviors that salespersons might employ when reacting with customers. Saxe and Weitz reported high levels of internal consistency reliability and presented evidence of convergent and discriminant validity.

Instructions for the SOCO scale asked individuals to describe ways in which they might act with a customer. However, we slightly altered the instructions and asked students to assume that they were working as a sales representative and to indicate how they believed they would actually deal with customers. Participants recorded their responses on a nine-point scale for each of the 24 items on the scale (Saxe and Weitz, 1982). A SOCO score for each respondent was derived by computing the mean across the 24 items of the scale.

Myers-Briggs Type Indicator. Individuals' psychological types were measured by administering the Myers-Briggs Type Indicator, Form G (MBTI) (Myers and Myers 1987). The MBTI is a forced-choice, self-reporting personality assessment instrument which is grounded in Jungian personality type theory. This instrument was used to measure the basic preferences of individuals regarding their psychological types and preferred decision-making styles. The MBTI has been widely used in research and applied settings (Gardner and Martinko, 1996; Ruble and Cosier, 1990). Carlson (1985) reported reasonable estimates of validity for the instrument.

\section{Procedure}

Subjects were asked to complete a three-part questionnaire and the MyersBriggs Type Indicator. The questionnaire consisted of the SOCO scale, a section designed to gather classification data, and a section for participants to record their psychological types as determined by the MBTI instrument. Differences among group mean responses of participants' psychological types were evaluated using the analysis of variance (ANOVA) technique. The SOCO variable was metric in nature, while personality types were treated as categorical variables.

\section{Results}

Means, standard deviations, and correlations of the variables employed in this study are presented in Table 1 . The results indicate statistically significant correlations $(\mathrm{p}<.01)$ between the S/N psychological types and SOCO scores and between T/F psychological types and SOCO scores. The mean SOCO score was 7.4 on a 9 -point scale $(9=$ high customer orientation), indicating that respondents appeared to be highly customer oriented. Individual mean scores across the 24 items on the SOCO scale ranged from 4.42 to 8.96 , with a standard deviation of 
.84. The SOCO mean scores in this study compare favorably with those reported by Saxe and Weitz (1982) (means of 7.6 and 7.7 for two samples).

Table 1

Descriptive Statistics and Pearson Correlation Matrix

\begin{tabular}{lcccccc}
\hline Variables & Means & s.d. & $\mathbf{1}$ & $\mathbf{2}$ & $\mathbf{3}$ & $\mathbf{4}$ \\
\hline 1. SOCO & 7.40 & .84 & 1.0000 & & & \\
2. S/N & .30 & .46 & $.2741^{* *}$ & 1.0000 & & \\
3. T/F & .37 & .48 & $.2435^{* *}$ & $.2290^{*}$ & 1.0000 & \\
\hline
\end{tabular}

$* \mathrm{p}<.05$

** $\mathrm{p}<.01$

SOCO $=$ Sales Orientation and Customer Orientation

$\mathrm{S} / \mathrm{N}=$ Sensing/Intuition Psychological Types

$\mathrm{T} / \mathrm{F}=$ Thinking/Feeling Psychological Types

s.d. = Standard Deviation

$\mathrm{S}=0, \mathrm{~N}=1$

$\mathrm{T}=0, \mathrm{~F}=1$

The MBTI instrument was used to determine the respondents' $\mathrm{S} / \mathrm{N}$ and $\mathrm{T} / \mathrm{F}$ orientations. The $S$ orientation was preferred by 69.7 percent of the respondents while 30.3 percent preferred the $\mathrm{N}$ orientation. The $\mathrm{T}$ orientation was preferred by 63.4 percent and the $F$ orientation was preferred by 36.6 percent. This distribution of psychological type preferences is consistent with previous studies of business students (Myers and McCaulley, 1985).

Mean SOCO scores by psychological types are presented in Table 2. As shown in the table, the $\mathrm{N}$ psychological group is more customer oriented than the $\mathrm{S}$ group, while the $\mathrm{F}$ group is more customer oriented than the $\mathrm{T}$ group.

Table 2

SOCO Scores by Psychological Types

\begin{tabular}{ccc}
\hline Psychological Type & Mean & s.d. \\
\hline S & 7.2213 & .8333 \\
N & 7.7185 & .6981 \\
T & 7.2051 & .8598 \\
F & 7.6296 & .7373 \\
\hline
\end{tabular}

The research questions were evaluated by testing for significant differences between the $\mathrm{S}$ and $\mathrm{N}$ psychological type groups by SOCO as well as between the 
$\mathrm{T}$ and $\mathrm{F}$ type groups by SOCO using an ANOVA model. The dependent variable was the SOCO scores, and the independent variables were the psychological type groups. The ANOVA results were statistically significant at the 0.05 level as shown in Table 3. The two-way interactions were not significant. These results confirm statistically significant differences between the $S$ and $N$ type groups when employing SOCO as a dependent variable. The $\mathrm{N}$ type group was more customer oriented than the $S$ type group. A statistically significant difference was also found between the $F$ type group and the $T$ type group, with the $F$ types being more customer oriented than the T types.

Table 3

Statistically Significant Differences Between $\mathrm{S} / \mathrm{N}$ and T/F Orientations

\begin{tabular}{lccccc}
\hline Source & df & $\begin{array}{c}\text { Sum of } \\
\text { Squares }\end{array}$ & $\begin{array}{c}\text { Mean } \\
\text { Square }\end{array}$ & $\begin{array}{c}\text { F } \\
\text { Stat. }\end{array}$ & $\begin{array}{c}\text { Prob. } \\
\text { F }\end{array}$ \\
\hline Main Effects & 2 & 5213.11 & 2602.55 & 7.29 & .001 \\
S/N & 1 & 2462.71 & 2462.71 & 6.88 & .010 \\
T/F & 1 & 1516.60 & 1516.60 & 4.24 & .042 \\
2-way Interactions & 1 & 1048.54 & 1048.54 & 2.93 & .089 \\
S/N T/F & & & & & \\
Error & 120 & 42934.29 & 357.78 & & \\
Total & 123 & 49195.93 & 399.96 & & \\
\hline
\end{tabular}

\section{Discussion, Conclusions, and Implications}

The purpose of this research was to determine whether or not individuals' innate customer orientation was related to their psychological type preferences. The primary psychological types under consideration were individuals' preferred method for gathering information from the external environment (sensing and intuition functions) and their preferred method for drawing conclusions and making decisions from the information (thinking and feeling functions).

More specifically, the first research question called for an evaluation of possible relationships between individuals' $S$ and $N$ preferences and their customer orientation. Results of this research indicate that customer orientation appears to be influenced by differing psychological types. A statistically significant difference in customer orientation was found between groups of individuals who preferred a sensing function compared with those who preferred an intuitive function. Those who preferred the intuitive function scored a higher mean SOCO value than did those who preferred the sensing function. As stated earlier, type theory holds that Ns prefer abstract information, whereas Ss favor concrete data and tend to think in terms of logical and objective data. Further, Ns tend to think in terms of possibilities and associations. They think beyond what is present in a 
situation and propose creative solutions to problems. Customer orientation calls for a person to diagnose customers' needs and propose creative solutions to their problems. The $\mathrm{N}$ psychological type preference appears to be consistent with highly customer-oriented behavior.

The second research question calls for an assessment of potential relationships between individuals' $T$ and $F$ preferences and their sales orientation-customer orientation. A statistically significant difference in customer orientation scores was found between groups of individuals who preferred a thinking function compared with those who preferred a feeling function. Individuals who preferred the feeling function scored a higher mean SOCO value than did those who preferred the thinking function. The thinking-feeling dichotomy reflects two different ways of judging information and making decisions. Individuals who prefer the thinking function focus on making decisions through the use of logical and objective data. For those who prefer a feeling function, the focus is on making decisions based on personal and subjective data. A customer-oriented approach calls for a salesperson to get to know customers and their needs and focus selling efforts on a customer's specific situation rather than using a single generic sales approach for all customers. Since a more personal approach is consistent with highly customer oriented behavior, the $\mathrm{F}$ psychological type preference appears to be consistent with a high level of customer orientation.

These findings have important implications for strategy implementation. The marketing concept may not be the best management philosophy for all organizations (Houston, 1986). But in many cases, an organization can be expected to consider optimal levels of concern with and responsiveness to customer needs as well as its internal capabilities in determining the extent to which it should adopt a customer orientation versus a sales orientation. Once an organization determines its appropriate marketing orientation-sales orientation strategy, an important part of strategy implementation is to motivate its salespeople to employ the chosen orientation in their selling tasks (Siguaw, et al., 1994).

An important implication of the findings of this research is that Myers-Briggs psychological type profiles could be a useful predictor of individuals' innate customer orientation. Individuals with $\mathrm{N}$ and F psychological type preferences were found to be more customer oriented than those with $\mathrm{S}$ and $\mathrm{T}$ psychological type preferences. Therefore, the Myers-Briggs type inventory, a paper and pencil test, could be a useful supplemental tool in recruiting and selecting salespeople. An organization could select salespersons whose personality type is compatible with its market orientation.

For example, recruitment of entry level salespeople might feature a personality type profile, and this profile could be useful as a supplement to the selection process rather than as the sole device employed. Since specific personality types were found to be related to customer orientation in this study, such a profile might also be useful in assessing training needs of presently employed salespeople. Additionally, personality type profiles might be useful as a way to assess training effectiveness. 
Finally, important limitations of the findings of the current study exist. First, the research should be repeated with professional salespersons. Though the student sample was appropriate for an exploratory study of linkages between innate personality types and SOCO scores, the results should be generalized with great care. Further, by asking students to assume that they were working as sales representatives, the subjects were role playing. A second limitation is the inability to draw causal inferences since all variables were measured simultaneously. Time sequence of the relationships cannot be determined with certainty.

\section{References}

Bass, K.E. and F.J. Hebert. "Psychological Types, Decision Styles, and Ethical DecisionMaking." Journal of Business Strategies 10 (Fall 93): 79-94.

Carlson, J.G. "Recent Assessments of the Myers-Briggs Type Indicator." Journal of Personality Assessment 49 (1985):356-365.

Dunlap, B.J., M.J. Dotson, and T.M. Chambers. "Perceptions of Real Estate Brokers and Buyers: A Sales-Orientation, Customer-Orientation Approach." Journal of Business Research 17 (1988): 175-187.

Gardner, W.L. and M.J. Martinko. "The Relationship between Psychological type, Managerial Behavior, and Managerial Effectiveness: An Empirical Investigation." Journal of Psychological Type 19 (1990): 35-43.

. "Using the Myers-Briggs Type Indicator to Study Managers: A Literature Review and Research Agenda." Journal of Management 22 (1996): 45-83.

Ginn, C.W. and D.L. Sexton. "A Comparison of the Personality Type Dimensions of the 1987 Inc. 500 Company Founders/CEOs With Those of Slower-Growth Firms." Journal of Business Venturing 5 (September 1990): 291-299.

Herden, R.P. and M.A. Lyles. "Individual Attributes and the Problem Conceptualization Process." Human Systems Management 2 (1981): 275-284.

Houston, F.S. "The Marketing Concept: What It Is and What It Is Not." Journal of Marketing 50 (April 1986): 81-87.

Hoy, F. and D. Hellriegel. "The Kilmann and Herden Model of Organizational Effectiveness Criteria for Small Business Managers." Academy of Management Journal 25 (1982): 308-322.

Jung, C.G. The Collected Works of C. G. Jung. Trans. H.G. Baynes, ed. R.C.F. Hull. Princeton, NJ: Princeton University Press, 1971. 
Kelley, S.W. "Developing Customer Orientation Among Service Employees." Journal of the Academy of Marketing Science 20 (1992): 27-36.

Kilmann, R.H. and K.W. Thomas. "Interpersonal Conflict-Handling Behavior as Reflections of Jungian Personality Dimensions." Psychological Reports 37 (1975): 971-980.

Kilmann, R.H. and I.I. Mitroff. "Qualitative Versus Quantitative Analysis for Management Science: Different Forms for Different Psychological Types." Interfaces 6 (1976): $16-27$.

Kohli, A.K. and B.J. Jaworski. "Market Orientation: The Construct, Research Propositions, and Managerial Implications." Journal of Marketing 54 (April 1990): 1-18.

Myers, I.B. and M.H. McCaulley. Manual: A Guide to the Development and Use of the Myers-Briggs Type Indicator. Palo Alto, CA: Consulting Psychologists Press, 1985.

Myers, I.B. and K.D. Myers. Myers-Briggs Type Indicator Form G. Palo Alto, CA: Consulting Psychologists Press, Inc., 1987.

Narver, J.C. and S.F. Slater. "The Effect of a Market Orientation on Business Profitability." Journal of Marketing 54 (October 1990): 20-35.

Nutt, P.C. "Strategic Decisions Made by Top Executives and Middle Managers with Data and Process Dominant Styles." Journal of Management Studies 27 (March 1990): 173 194.

O'Hara, B.S., J.S. Boles, and M.W. Johnston. "The Influence of Personal Variables on Salesperson Selling Orientation." Journal of Personal Selling and Sales Management XI (1991): $62-67$.

Porter, L. and R. Miles. "Motivation and Management." In Contemporary Management: Issues and Viewpoints. ed. Joseph McGuire. Englewood Cliffs, NJ: Prentice Hall, 1974.

Ruble, T.L. and R.A. Cosier. "Effects of Cognitive Styles and Decision Setting on Performance." Organizational Behavior and Human Decision Processes 46 (1990): 283-295.

Sager, J.K. and G.R. Ferris. "Personality and Salesforce Selection in the Pharmaceutical Industry." Industrial Marketing Management 15 (1986); 319-324.

Saxe, R., and B.A. Weitz. "The SOCO Scale: A Measure of the Customer Orientation of Salespeople." Journal of Marketing Research 19 (August 1982): 343-351.

Siguaw, J.A., G. Brown, and R.E. Widing II. "The Influence of the Market Orientation of the Firm on Sales Force Behavior and Attitudes." Journal of Marketing Research 31 (February 1994): 106-116. 
Williams, M.R. and J. Wiener. "Does the Selling Orientation-Customer Orientation (SOCO) Scale Measure Behavior or Disposition?" In Enhancing Knowledge Development in Marketing, eds. W. Bearden, et al, 239-242 Chicago: American Marketing Association, 1990.

Kenneth E. Bass, D.B.A. (Louisiana Tech) is Assistant Professor of Management at East Carolina University. He has published articles in several journals, including the Journal of Business Strategies, Journal of Business Ethics and Journal of Personal Selling and Sales Management. His research interests include ethical decision making, ethical strategy, and total quality management.

Frederic J. Hebert, D.B.A. (Louisiana Tech) is Associate Professor of Management at East Carolina University. He has published articles in several journals, including the Journal of Small Business Management, SAM Advanced Management Journal and the Journal of Business \& Entrepreneurship. His research interests include the application of psychological type theory to managerial practice, as well as various topics relating to entrepreneurship and small business management. 